\title{
Language delay and poorer school performance in children of mothers with inadequate iodine intake in pregnancy: results from follow-up at 8 years in the Norwegian Mother and Child Cohort Study
}

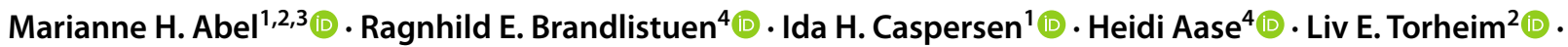 \\ Helle Margrete Meltzer ${ }^{1}$ (D) . Anne Lise Brantsaeter ${ }^{1}$ (D)
}

Received: 20 June 2018 / Accepted: 29 October 2018 / Published online: 12 November 2018

(c) The Author(s) 2018

\begin{abstract}
Purpose Some studies indicate that mild-to-moderate iodine deficiency in pregnant women might negatively affect offspring neurocognitive development, including previous results from the Norwegian Mother and Child Cohort study (MoBa) exploring maternally reported child development at age 3 years. The aim of this follow-up study was to investigate whether maternal iodine intake in pregnancy is associated with language and learning at 8 years of age.

Methods The study sample includes 39,471 mother-child pairs participating in MoBa with available information from a validated food frequency questionnaire covering the first half of pregnancy and a questionnaire on child neurocognitive development at 8 years. Multivariable regression was used to explore associations of iodine intake from food and supplements with maternally reported child outcomes.

Results Maternal iodine intake from food less than $\sim 150 \mu \mathrm{g} / \mathrm{day}$ was associated with poorer child language skills ( $p$-overall $=0.013)$, reading skills ( $p$-overall $=0.019)$, and writing skills $(p$-overall $=0.004)$ as well as poorer school test result in reading $(p<0.001)$, and increased likelihood of the child receiving special educational services ( $p$-overall $=0.042)$ (in noniodine supplement users). Although significant, differences were generally small. Maternal use of iodine supplements in pregnancy was not significantly associated with any of the outcomes.

Conclusions Low habitual iodine intake in pregnant women, i.e., lower than the recommended intake for non-pregnant women, was associated with mothers reporting poorer child language, school performance, and increased likelihood of special educational services. We found no indications of benefits or harm of using iodine-containing supplements in pregnancy. Initiating use in pregnancy might be too late.
\end{abstract}

Keywords Iodine · Pregnancy · Dietary supplements · Neurodevelopment · Norwegian Mother and Child Cohort Study · MoBa

Electronic supplementary material The online version of this article (https://doi.org/10.1007/s00394-018-1850-7) contains supplementary material, which is available to authorized users.

Anne Lise Brantsaeter

annelise.brantsaeter@fhi.no

1 Division of Infection Control and Environmental Health, Department of Exposure and Environmental Epidemiology, Norwegian Institute of Public Health, Skøyen, P.O. Box 222, 0213 Oslo, Norway

2 Department of Nursing and Health Promotion, Faculty of Health Sciences, Oslo Metropolitan University, St. Olavs plass, P.O. Box 4, 0130 Oslo, Norway

\author{
Abbreviations \\ EAR Estimated average requirement \\ FFQ Food frequency questionnaire \\ GW Gestational week \\ ID Iodine deficiency
}

3 Department of Nutrition, Tine, SA, P.O. Box 25, 0051 Oslo, Norway

4 Division of Mental and Physical Health, Norwegian Institute of Public Health, Skøyen, P.O. Box 222, 0213 Oslo, Norway 
MoBa The Norwegian Mother and Child Cohort Study

UIC Urinary iodine concentration

\section{Introduction}

Iodine is an essential micronutrient incorporated into the thyroid hormones thyroxine (T4) and triiodothyronine (T3). Thyroid hormones are vital in the regulation of early brain development, and the developing foetus is vulnerable to low maternal T4, especially before the foetal thyroid starts to function in gestational week (GW) 18-20 [1]. Iodine status is an important determinant of risk for thyroid disorders and, as a result, abnormal thyroid hormone concentrations [2-4]. In mild-to-moderate iodine deficiency (ID), a range of autoregulatory mechanisms are triggered in the maternal thyroid to maintain the production and release of the hormones [5]. To conserve iodine, more T3 is released and less T4. The resulting maternal hypothyroxinaemia (i.e., low/suboptimal T4) may reduce foetal supply of the hormones since the direct transfer of maternal T3 over the placenta is extremely low [1].

Globally, ID is one of the most prevalent nutrient deficiencies, common in both low and high income countries [6]. Substantial efforts have been made to eradicate ID, and today the number of countries with severe ID populations has declined [7]. Still, mild-to-moderate ID is prevalent in many regions, and particularly in pregnant women, as the recommended intake in pregnancy is higher. The iodine requirement increases in pregnancy due to a higher production of thyroid hormones, an increase in renal iodide clearance, and trans-placental iodine transfer $[8,9]$. In 2007, the World Health Organisation (WHO) reported that an estimated $50 \%$ of the population in continental Europe remains mildly iodine deficient [10].

Results from animal studies and observational human studies, including the Norwegian Mother and Child Cohort Study $(\mathrm{MoBa})$, indicate that maternal mild-to-moderate ID might affect thyroid function in pregnancy [11], and negatively affect foetal neurodevelopment including reduced IQ, school performance, language delay, and behaviour problems [1, 12-17]. When children do not reach their full developmental potential due to ID, this is not only important for the children's future, but also costly at a societal level [18].

Although studies indicate negative effects, there is little knowledge about what is the optimal iodine intake to secure an adequate iodine status in pregnant women. Thus, different recommendations for daily intake during pregnancy exist. In the Nordic countries, $175 \mu \mathrm{g} /$ day is recommended [19], whereas the European Food Safety Authority recommendation is $200 \mu \mathrm{g} / \mathrm{day}$ [20], and the WHO recommendation is $250 \mu \mathrm{g} /$ day [21]. Additionally, studies show conflicting results as to whether iodine supplement use initiated in pregnancy is beneficial or potentially harmful in mild-to-moderate ID populations [22]. Iodine supplements can reduce the risk of thyroid enlargement due to ID, but some studies, including results from $\mathrm{MoBa}$, indicate that a sudden increase in iodine intake may temporary inhibit thyroid hormone production and cause lower availability of T4 to the foetus [11,23, 24]. In MoBa, we observed an increased risk of child ADHD symptoms and diagnosis at age 6-13 years in children of mothers who had initiated use of iodine-containing supplements in the first trimester [13], but no effect on language and motor skills at age 3 years [12].

In this follow-up of the MoBa-children, the main aim was to investigate associations between maternal iodine intake in pregnancy (from food or from supplements) and child language and learning at age 8 years. A second aim was to evaluate current iodine status in a subsample of 300 8-yearsold children.

\section{Materials and methods}

\section{Subjects and design}

This study is based on the Norwegian Mother and Child Cohort Study (MoBa) conducted by the Norwegian Institute of Public Health [25]. Women pregnant in their first trimester were recruited from all over Norway during the years 1999-2008 and were asked to answer questionnaires (in Norwegian) at regular intervals during pregnancy and after birth. More than $99 \%$ of participants are of Caucasian origin. Pregnancy and birth records from the Medical Birth Registry of Norway are linked to the MoBa database [26]. The women consented to participation in $41 \%$ of the pregnancies. The cohort now includes 114,500 children, 95,200 mothers and 75,200 fathers. The current study is based on version 10 of the quality-assured data files released for research in 2017 and includes participants with data from the 8 -year questionnaire $(n=39,471)$. A flow chart of inclusion is illustrated in Fig. 1. A subsample of 8-years-old MoBa-children living in Oslo and the surrounding areas were recruited for an EU-project [27] and contributed with urine samples for analysis of UIC $(n=279)$.

\section{Exposure variable: iodine intake}

The MoBa FFQ [28] was specifically designed for the MoBa study and in use from 2002. It is a semi-quantitative questionnaire designed to capture dietary habits and use of dietary supplements during the first half of pregnancy 


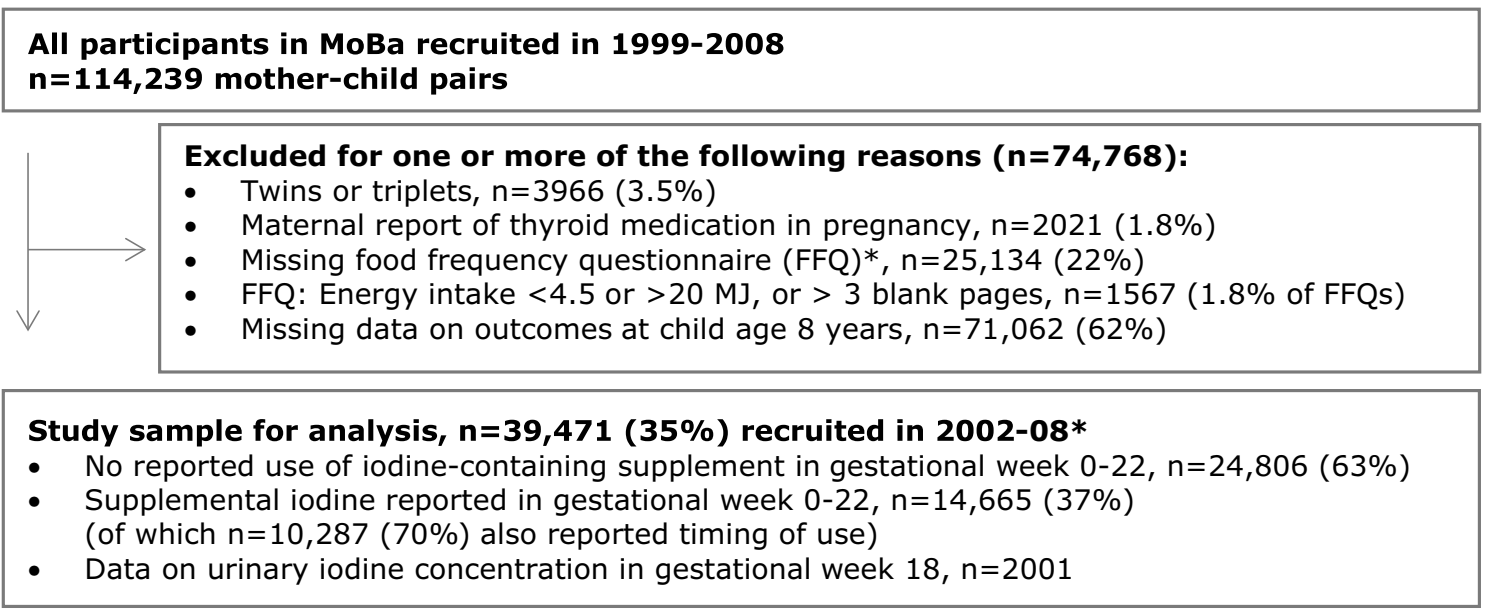

Fig. 1 Flow chart of inclusion. *The MoBa food frequency questionnaire was introduced in March 2002

[29] and was completed by participating women around GW 22. It included questions about intake of 255 food items or dishes. The average intake of specific foods and nutrients in GW 0-22 were calculated based on standard Norwegian portion sizes, the Norwegian food composition table, analyses of Norwegian food samples [30, 31], and data on the content of more than 1000 food supplements collected from suppliers [32]. There is limited data on dosage of supplements since the wording of the question on supplement use in the MoBa FFQ was unclear as to which time period it referred to (i.e., average intake in GW 0-22, intake only when using, or current use in GW 22). Therefore, we decided not to use the dosage of supplement as an exposure variable, but instead included it as a dichotomous variable (use/no use in GW 0-22).

As reported previously [12], the MoBa FFQ has been shown to be a valid tool for ranking pregnant women according to high and low intakes of energy, nutrients and foods [33]. Iodine was validated separately and iodine intake by the FFQ, including supplemental iodine, agreed well with the reference methods 24-h UIE and 4 days weighed-food diary, triangular validity coefficient for total iodine intake by the FFQ was 0.62 (95\% CI 0.46, 0.77) $[34,35]$.

Timing of iodine supplement use was reported in the general questionnaires answered in GW 17 and GW 30. Timing of the first reported use was coded in four categories (never, week $0-26$ before pregnancy, GW 0-12 and GW 12-22).

Blood and spot-urine samples were collected at the routine ultrasound examination offered free of charge to all Norwegian women in GW 18, and urinary iodine concentration (UIC) was measured for a subsample of the women $(n=2001)$ as an alternative measure of iodine intake.

UIC was also measured in a subgroup of 8-year-old children in MoBa residing in the Oslo area $(n=279$, year of sampling 2014-2015) in a urine sample where equal volumes of an evening urine and the following morning urine were mixed.

\section{Outcome variables: child language and learning}

Outcomes were based on the MoBa questionnaire completed by the mothers at child age 8 years. The questionnaire was distributed to all participants in MoBa by mail and the response rate was $38 \%$.

\section{Maternally reported language skills}

A standardized score was calculated based on items from The Children's communication checklist-Short (CCC-S), a brief version of the CCC-2 [36]. The full CCC-2 is as effective as a standardized assessment in identifying children with clinically significant language impairment [37]. The CCC-S contains 13 items that best discriminated typically developing children from peers with language impairment in the validation study [38], with high degrees of internal consistency (Cronbach's $\alpha=0.80$, this sample) and a significant correlation between CCC-S and CCC-2 total scores in the standardization sample, Pearson's $r=0.88$. Each item provides an example of language behaviour in everyday contexts and covers speech, vocabulary, grammar and discourse.

\section{Maternally reported child reading and writing skills}

Standardized scores were calculated based on three items on reading skills: (1) reads simple stories aloud, with ease, when asked, (2) identifies all lowercase and uppercase printed letters of the alphabet, (3) reads and understands texts suitable for 7-8 years olds, and two questions on writing skills: (1) writes simple information/messages at least 
three sentences long, (2) writes reports, papers, or essays at least one page long; may use computer. May make small errors in spelling or sentence structure. Items were selected from the written sub-scale of the Vineland Adaptive Behaviour Scale-II [39]. Mothers answered "yes", "partially", or "not yet" which was coded as 0,1 , and 2 .

\section{Mandatory mapping tests in reading and mathematics in first and/or second grade in school}

Performance tests in reading, writing, and mathematics are conducted in first and second grade. The tests map the ability to write letters, recognize written letters, identify spoken letters, combine sounds, write words, read words and read sentences. The mathematics test maps the ability to count, to compare numbers, to rank numbers, to recognize sequences of numbers, to count forward and backward from a given number, to split a number into two other numbers, to solve textual assignments and to add two numbers. Mothers were asked if they were informed by the teacher about their child's performance on the mapping tests. Alternative answers were "masters subject well", "must work more but teacher is not concerned", "teacher is concerned", or "don't know/not discussed with teacher".

\section{Special education}

Child granted special education in school (extra educational services) due to disabilities or learning difficulties was reported by the mother (yes/no).

\section{Covariates}

Covariates were included in the models based on previous knowledge and directed acyclic graphs (DAGs). Data on covariates were obtained from different sources: maternal age and child sex was obtained from the Medical Birth Registry of Norway. Maternally reported pre-pregnancy body weight and height for the calculation of body mass index (BMI), maternal education ( $\leq 12,13-16, \geq 17$ years), parity (previous pregnancies $\geq 22$ weeks: $0,1, \geq 2$ ), maternal chronic illness [asthma, diabetes, inflammatory bowel disease, rheumatic disease, epilepsy, multiple sclerosis or cancer before or during pregnancy (yes/no)], bilingual parent(s) (yes/no), and use of a folic acid supplement within the interval from 4 weeks before to 8 weeks after conception (yes/ no) were included from questionnaire 1. Energy intake, fibre intake (as a marker of a healthy dietary pattern), and intake of the omega-3 fatty acids EPA and DHA were calculated based on the FFQ. Information on smoking in pregnancy was obtained from questionnaire 1 and, if available, questionnaires 3 (GW 30) and 4 (child's age 6 months) (three categories: no reported smoking in pregnancy, reported occasional smoking or stopped smoking before GW 12, and daily smoking at any time in pregnancy and had not stopped smoking before GW 12). Maternal history of reading or writing difficulties (yes/no) was retrieved from the 8 years questionnaire. Paternal history of reading and writing difficulties is not reported in MoBa. Child ADHD symptoms was defined as the mean score on 18 items from the ADHD Rating Scale included in the 8-year questionnaire.

\section{Laboratory procedures}

UIC was determined at the National Institute for Health and Welfare in Helsinki, Finland by inductively coupled plasma-mass spectrometry using an Agilent 7800 ICP-MS system (Agilent Technologies Inc, Santa Clara, CA, USA). The limit of quantification was $2 \mu \mathrm{g} / \mathrm{L}$ and the linearity was excellent up to $1500 \mu \mathrm{g} / \mathrm{L}(r=0.99)$. Coefficient variation was $2-3 \%$.

\section{Statistics}

Statistical analyses were performed in STATA (version 15.0; Stata Corp., College Station, TX).

In total, $4.2 \%$ of the women had missing values on pre-pregnancy BMI $(n=956,2.4 \%)$, maternal education $(n=839,2.1 \%)$, or on all covariates from questionnaire 1 ( $n=107,0.3 \%$ ) including parity, marital status, chronic illness, bilingual parent(s), and folic acid supplement use. Missing values for covariates were imputed using multiple imputation by chained equations in STATA, and 20 imputed datasets were generated for analyses.

Associations were estimated by generalized linear regression (gamma family) for the continuous outcomes (language-, reading-, and writing scores), logistic regression for the dichotomous outcome special education, and ordered logistic regression for the ordinal outcomes (mandatory school mapping tests in reading and mathematics). Associations between iodine from food and the outcomes were modelled flexibly by restricted cubic splines (four knot positions, at percentiles 5, 35, 65, and 95). All models were adjusted for random effects of sibling clusters since some women participated with more than one pregnancy.

Adjusted models included the following covariates based on a causal diagram (Supplementary Figure S1, Online Resource 1): maternal age, education, parity, pre-pregnancy BMI, energy intake, fibre intake, and smoking in pregnancy. Models with continuous outcomes also included the following covariate(s) to increase the precision of the estimates: child sex, bilingual parent(s) (for the language outcome), and maternal history of reading/writing difficulty (for read/write scores). To isolate the effect of long-term/habitual iodine intake, we restricted analysis on associations between iodine intake from food and outcomes to participants who had not 
reported any use of supplemental iodine in gestational week $0-22$.

The potential impact of iodine supplement use was explored by including an interaction-term between iodine from food (modelled by restricted cubic splines) and (1) any supplement use in GW 0-22 and (2) timing of first reported use (never, initiation 1-26 weeks before conception, gestational week 0-12, or gestational week 13-22). If interactions were not significant, iodine from food was not included in the final models. Adjusted models on supplement use additionally included the covariates total intake of the $n-3$ fatty acids EPA and DHA (from food and dietary supplements), and maternal use of folic acid supplements within the interval from 4 weeks before to 8 weeks after conception.

Associations between maternal UIC (in $\mu \mathrm{g} / \mathrm{L}$ ) and child outcomes were also explored in multivariable regression models.

$p$ values are reported for overall associations between continuous exposures and outcomes (testing $\mathrm{HO}$ : no association) by testing the coefficients of all spline transformations equal to zero. The tests for non-linearity were performed by testing the coefficients of the second and third spline transformations equal to zero. Potential interactions were explored by testing all interaction coefficients equal to zero. All statistical tests were performed on the imputed datasets $(n=20)$.

Results are reported including robust $95 \%$ confidence intervals (CI). A $p$ value $<0.05$ was considered statistically significant. Sensitivity analysis included adjusting for score on 18 items from the ADHD symptoms checklist to see if the associations were also independent of effect on ADHD symptom score at age 8 years reported in a previous publication [13].

\section{Results}

Characteristics of the study population are shown in Table 1, and calculated iodine intake and UIC by background characteristics are shown in Supplementary Table S1 (Online Resource 1). At a group level, maternal iodine intake in pregnancy was insufficient according to WHO guidelines (i.e., iodine intake was $<250 \mu \mathrm{g} /$ day and median UIC $<150 \mu \mathrm{g} / \mathrm{L}$ ) [21], and also according to EFSA and Nordic guidelines $[19,20]$. The calculated median iodine intake from food was $122 \mu \mathrm{g} /$ day (IQR 89, $161 \mu \mathrm{g} /$ day), and median UIC (mean GW 18.5 (SD 1.3)) was $67 \mu \mathrm{g} / \mathrm{L}$. Women who reported use of iodine-containing supplements at the time of UIC sampling had higher UIC (median $95 \mu \mathrm{g} / \mathrm{L}$ vs. $59 \mu \mathrm{g} / \mathrm{L}$ in non-users, $p<0.001$ ). Median iodine intake from food differed only slightly by background characteristics, and did not differ between supplement users (37\%) and non-supplement users (63\%), between women with and without UIC measurements, or between responders and nonresponders to the questionnaire at 8 years (Table 1). The major dietary sources of iodine were milk/yoghurt (47\%), other dairy products (13\%), and lean fish (14\%). Drinking water only contributed with $2 \%$, egg with $4 \%$, fatty fish with $4 \%$, and all other foods with the remaining $17 \%$. Food sources of iodine by categories of iodine intake from food are shown in Supplementary Figure S2 (Online Resource 1). Iodine supplement use was more commonly reported in nulliparous (43\%), higher educated (40\%), and high-income households (40\%) than in primi- or multiparous, less highly educated and lower-income groups (all $p<0.001$ ), but the differences were generally small. UIC was higher in supplement users $(p<0.001)$, but did not differ significantly by any other background characteristic (Supplementary Table S1, Online Resource 1). The Spearman correlation between iodine intake by the FFQ and UIC (in $\mu \mathrm{g} / \mathrm{g}$ creatinine) was $r=0.31$ (95\% CI 0.26, 0.36).

UIC measured in the subsample of 8-year-old MoBa-children $(n=279)$ indicated adequate iodine intake in the children (median UIC: $110 \mu \mathrm{g} / \mathrm{L}$, IQR: 79, $155 \mu \mathrm{g} / \mathrm{L}$ ). According to WHO criteria [21], median UIC $>100 \mu \mathrm{g} / \mathrm{L}$ is characterized as adequate in school-age children.

In our study sample, $6.9 \%$ of the 8 year olds were granted special education at school. According to the mother, $28 \%$ had suboptimal or low score on the mandatory mapping test in school in reading, and $18 \%$ had suboptimal or low score in mathematics. All outcome measures were correlated or partially overlapping. Maternally reported child language skills was correlated with reading skills (Spearman $r=0.26, p<0.001$ ) and writing skills (Spearman $r=0.29, p<0.001$ ). Among children receiving special educational services, $85 \%$ had suboptimal scores on the mapping tests in reading (81\%) and/or mathematics $(56 \%)$. We have previously reported significant associations of maternal iodine intake with child ADHD-symptoms reported in the same 8-year questionnaire [13]. ADHD-symptoms correlated with child language skills (Spearman $r=0.35, p<0.001$ ), and $31 \%$ of children with special education scored $>1.5$ SD on ADHD symptoms. Venn diagrams further illustrating overlaps between outcomes are provided in Supplementary Figures S3-S6 (Online Resource 1).

We have previously reported that maternal iodine intake was associated with child language skills at age 3 years [12]. Eighty-one percent of the participants in the current sample were also included in the 3-year sample. Compared to those with normal language skills at 3 years $(96 \%)$, children with mild to moderate language delay at 3 years $(3.1 \%)$ scored on average 1.2 SD higher on the language score (CCC-S) at 8 years $(95 \%$ CI 1.1, 1.3), and those with severe language delay at 3 years $(0.7 \%)$ scored 2.8 SD higher $(95 \%$ CI 2.3 , 
Table 1 Descriptive characteristics of the study population $(n=39,471$ mother-child pairs) by maternal iodine intake

\begin{tabular}{|c|c|c|c|c|c|c|c|}
\hline & \multicolumn{3}{|c|}{ Iodine from food, non-supplement users } & \multicolumn{2}{|c|}{$\begin{array}{l}\text { Iodine supplement use in preg- } \\
\text { nancy (week 0-22) }\end{array}$} & \multirow[t]{2}{*}{ All } & \multirow[t]{2}{*}{ Whole $\mathrm{MoBa}^{\mathrm{a}}$} \\
\hline & $<100 \mu \mathrm{g} /$ day & $100-150 \mu \mathrm{g} /$ day & $>150 \mu \mathrm{g} /$ day & No & Yes & & \\
\hline $\begin{array}{l}\text { Study sample, } \\
n(\%)\end{array}$ & $8096(21)$ & $9126(23)$ & $7584(19)$ & $24,806(63)$ & $14,665(37)$ & $39,471(100)$ & 101,784 \\
\hline $\begin{array}{l}\text { Maternal age at } \\
\text { delivery, mean } \\
\text { (SD), years }\end{array}$ & $30.5(4.4)$ & $30.8(4.3)$ & $30.6(4.5)$ & $30.6(4.4)$ & $30.6(4.4)$ & $30.6(4.4)$ & $30.2(4.6)$ \\
\hline $\begin{array}{l}\text { Pre-pregnancy } \\
\text { BMI, mean } \\
\text { (SD), } \mathrm{kg} / \mathrm{m}^{2}\end{array}$ & $24.1(4.2)$ & $23.8(4.0)$ & $23.9(4.0)$ & $23.9(4.0)$ & $23.7(4.1)$ & $23.8(4.1)$ & $24.0(4.3)$ \\
\hline \multicolumn{8}{|l|}{ Parity, \% } \\
\hline 0 & 46 & 42 & 41 & 43 & 54 & 47 & 47 \\
\hline 1 & 37 & 37 & 37 & 37 & 32 & 35 & 36 \\
\hline 2 or more & 17 & 20 & 22 & 19 & 13 & 17 & 18 \\
\hline \multicolumn{8}{|c|}{ Maternal education, $\%$} \\
\hline$\leq 12$ years & 27 & 24 & 27 & 26 & 22 & 24 & 32 \\
\hline $13-16$ years & 43 & 45 & 46 & 45 & 45 & 45 & 41 \\
\hline$>16$ years & 28 & 29 & 25 & 27 & 31 & 29 & 25 \\
\hline Other/missing & 2.5 & 1.9 & 2.1 & 2.2 & 2.1 & 2.1 & 2.1 \\
\hline $\begin{array}{l}\text { Married/cohabit- } \\
\text { ant, } \%\end{array}$ & 97.1 & 97.5 & 96.9 & 97.2 & 96.9 & 97.1 & 96.1 \\
\hline \multicolumn{8}{|c|}{ Smoking in pregnancy, $\%$} \\
\hline Occasionally & 15 & 14 & 14 & 14 & 15 & 14 & 17 \\
\hline Daily & 4.1 & 3.4 & 4.0 & 3.8 & 3.0 & 3.5 & 5.7 \\
\hline $\begin{array}{l}\text { Chronic illness, } \\
\%\end{array}$ & 11.1 & 8.7 & 8.4 & 9.4 & 10.8 & 9.9 & 10.2 \\
\hline \multicolumn{8}{|c|}{ Household income, $\%$} \\
\hline Low & 24 & 24 & 27 & 25 & 23 & 24 & 29 \\
\hline Medium & 41 & 42 & 43 & 42 & 41 & 42 & 41 \\
\hline High & 33 & 32 & 27 & 31 & 34 & 32 & 28 \\
\hline Missing & 2.3 & 2.1 & 2.9 & 2.4 & 2.1 & 2.3 & 3.1 \\
\hline $\begin{array}{l}\text { Bilingual } \\
\text { parent(s), } \%\end{array}$ & 9.8 & 9.5 & 7.6 & 9.0 & 10.8 & 9.7 & 10.8 \\
\hline $\begin{array}{l}\text { Maternal history } \\
\text { of reading/ } \\
\text { writing dif- } \\
\text { ficulties (\%) }\end{array}$ & 6.2 & 4.8 & 5.4 & 5.4 & 5.4 & 5.6 & - \\
\hline $\begin{array}{l}\text { Child sex boy } \\
(\%)\end{array}$ & 51.4 & 51.1 & 51.5 & 51.3 & 50.2 & 50.9 & 51.2 \\
\hline $\begin{array}{l}\text { Iodine from } \\
\text { food, median } \\
\text { (IQR), } \mu \mathrm{g} / \text { day }\end{array}$ & $78(63,89)$ & $123(111,136)$ & $182(163,212)$ & $122(90,161)$ & $121(89,160)$ & $122(89,161)$ & $121(89,161)^{b}$ \\
\hline $\begin{array}{l}\text { UIC, median } \\
\text { (IQR), } \mu \mathrm{g} / \mathrm{L}^{\mathrm{c}}\end{array}$ & $47(26,85)$ & $62(33,105)$ & $70(39,116)$ & $59(32,101)$ & $83(43,138)$ & $67(35,115)$ & - \\
\hline $\begin{array}{l}\text { Urinary creati- } \\
\text { nine, median } \\
(90 \% \text { range }) \\
\mathrm{g} / \mathrm{L}^{\mathrm{c}}\end{array}$ & $0.75(0.17,2.00)$ & $0.76(0.16,1.88)$ & $0.72(0.21,1.89)$ & $0.75(0.17,1.92)$ & $0.72(0.16,1.87)$ & $0.74(0.17,1.90)$ & - \\
\hline $\begin{array}{l}\text { UIC, median } \\
\text { (IQR), } \mu \mathrm{g} / \mathrm{g} \\
\text { creatinine }^{\mathrm{c}}\end{array}$ & $69(44,97)$ & $83(58,115)$ & $99(72,132)$ & $83(56,115)$ & $116(75,187)$ & $91(63,139)$ & - \\
\hline $\begin{array}{l}\text { Iodine supple- } \\
\text { ment }(\%)\end{array}$ & 0 & 0 & 0 & 0 & 100 & 37 & $37^{\mathrm{b}}$ \\
\hline
\end{tabular}


Table 1 (continued)

\begin{tabular}{|c|c|c|c|c|c|c|c|}
\hline & \multicolumn{3}{|c|}{ Iodine from food, non-supplement users } & \multicolumn{2}{|c|}{$\begin{array}{l}\text { Iodine supplement use in preg- } \\
\text { nancy (week 0-22) }\end{array}$} & \multirow[t]{2}{*}{ All } & \multirow[t]{2}{*}{ Whole $\mathrm{MoBa}^{\mathrm{a}}$} \\
\hline & $<100 \mu \mathrm{g} /$ day & $100-150 \mu \mathrm{g} /$ day & $>150 \mu \mathrm{g} /$ day & No & Yes & & \\
\hline $\begin{array}{l}\text { Folic acid sup- } \\
\text { plement }(\%)^{\mathrm{d}}\end{array}$ & 71 & 71 & 68 & 70 & 84 & 75 & 69 \\
\hline $\begin{array}{l}\text { Omega } 3 \text { supple- } \\
\text { ment }(\%)\end{array}$ & 79 & 81 & 82 & 81 & 80 & 80 & $79^{\mathrm{b}}$ \\
\hline $\begin{array}{l}\text { Maternal energy } \\
\text { intake, median } \\
\text { (IQR), MJ }\end{array}$ & $8.0(6.9,9.3)$ & $9.2(8.1,10.6)$ & $11.0(9.6,12.8)$ & $9.3(7.9,11.0)$ & $9.3(7.9,11.0)$ & $9.3(7.9,11.0)$ & $9.4(7.9,11.1)$ \\
\hline
\end{tabular}

3.2). Higher scores at 8 years indicated poorer language skills.

\section{lodine from food and outcomes}

Low maternal iodine intake from food was associated with the child having poorer skills in language, reading, and writing, and increased likelihood of special education (Figs. 2, 3 ). There was also a tendency for a lower performance in mathematics (Fig. 3b), but the association was not statistically significant $(p=0.083)$. Combined, the spline graphs indicated that habitual iodine intakes lower than about $150 \mu \mathrm{g} /$ day was associated with lower child performance. Tabular results of the estimated associations are provided in Table 2.

Sensitivity analyses showed that associations were somewhat attenuated when adjusting for ADHD-symptoms at 8 years (Supplementary Figures S9 and S10, Online Resource 1), but remained largely the same (language skills and writing skills were no longer significant).

Maternal UIC in mid pregnancy (measured in a subgroup, $n=2001$ ) was not significantly associated with any of the outcomes (Supplementary Figures S11 and S12, Online Resource 1), and adjustment for urinary creatinine to adjust for hydration level did not change the results (results not shown).

\section{lodine from supplements}

There was no evidence of any associations between maternal use of iodine-containing supplements and child outcomes (Supplementary Table 2, Online Resource 1). Interaction with iodine from food was tested, but there was no indication of interaction for any of the outcomes. Iodine intake from food did not differ by supplement use (including by timing of supplement use).

\section{Discussion}

The main finding in this study is that low maternal habitual iodine intake (i.e., lower than $\sim 150 \mu \mathrm{g}$ /day from food) was associated with poorer maternally reported child performance, i.e., the child having poorer skills in language, reading, and writing, and also increased likelihood of the child receiving special education services. This finding is alarming and corroborate the previous findings in $\mathrm{MoBa}$ of increased risk of maternally reported language delay at child age 3 years [12]. Further, we did not detect any association between maternal iodine supplement use and child outcomes.

\section{lodine intake from food and outcomes}

Our findings suggest that impairments associated with mildto-moderate ID in pregnancy persist although iodine intake is adequate in childhood (indicated by the subgroup median child UIC > $100 \mu \mathrm{g} / \mathrm{L}$ ). Experimental animal studies have demonstrated that mild gestational ID can cause permanent neurological alterations in the developing brain [1]. Our findings are also supported by an observational study in Australia ( $n=228$, median gestational UIC: $81 \mu \mathrm{g} / \mathrm{L})$ where children of mothers with gestational UIC $<150 \mu \mathrm{g} / \mathrm{L} \mathrm{had}$ poorer educational outcomes (spelling, grammar and English-literacy) at age 9 years than peers whose mothers did not have mild or moderate gestational ID (i.e., UIC $\geq 150 \mu \mathrm{g} / \mathrm{L}$ ), even though the children were iodine sufficient in childhood [15]. A follow-up study demonstrated that the reduced educational performance persisted also at 15 years of age [16]. Bath et al. found that children of mothers with a suboptimal 

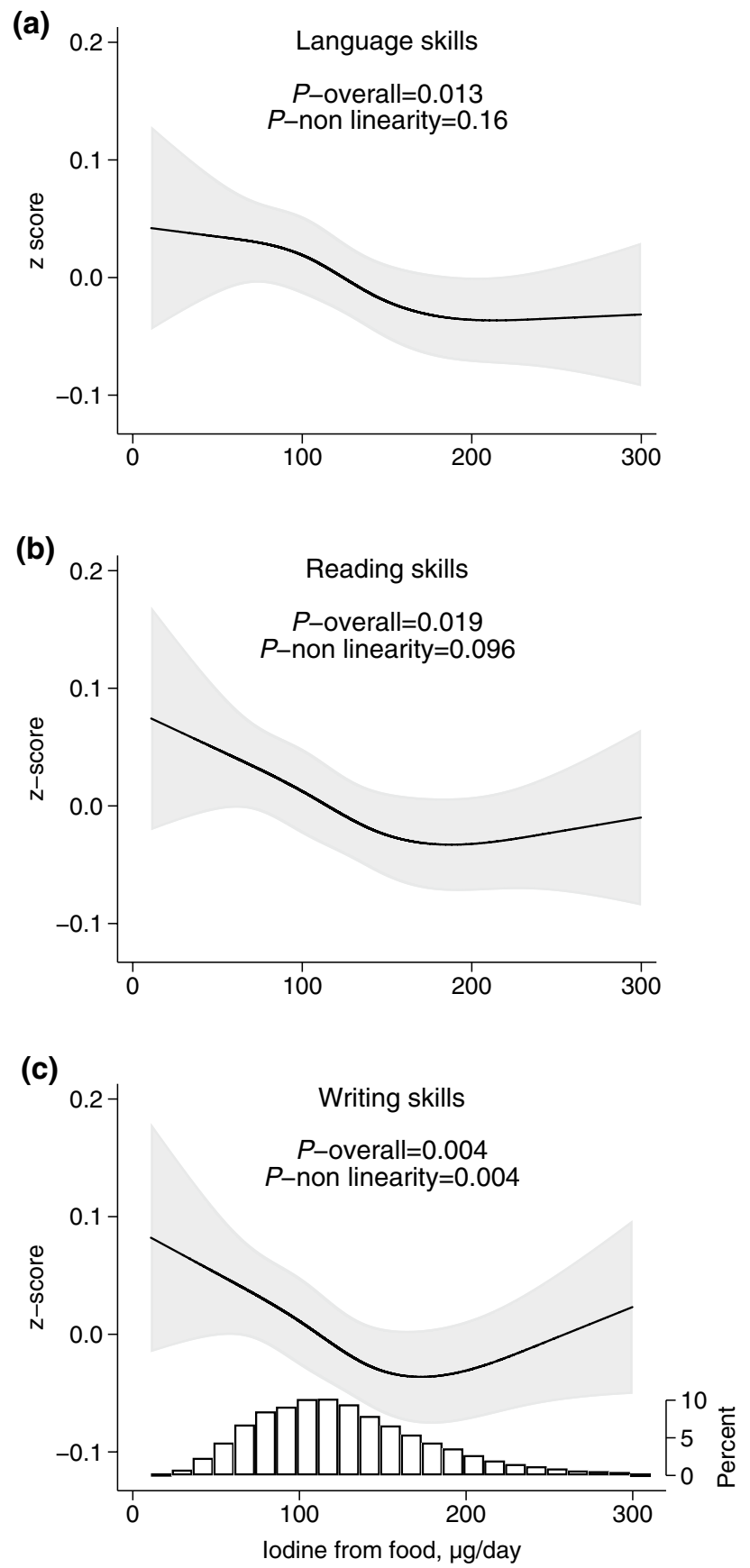

Fig. 2 Maternal iodine intake from food (in non-supplement users) and child skills in language (a, $n=24,643)$, reading (b, $n=19,492)$, and writing (c, $n=19,483)$, adjusted models. Higher $z$ scores indicate poorer skills. The histogram in $\mathbf{c}$ represents the distribution of iodine intake. For crude models, see Supplementary Figure S7 (Online Resource 1)

UIC in pregnancy $(<150 \mu \mathrm{g} / \mathrm{g}$ creatinine $)$ had a lower IQ and reading ability at child age $8-9$ years in a UK cohort ( $n=1040$, median gestational UIC: $91 \mu \mathrm{g} / \mathrm{L})$ [14]. However, limitations of these studies were that spot-UIC was the only
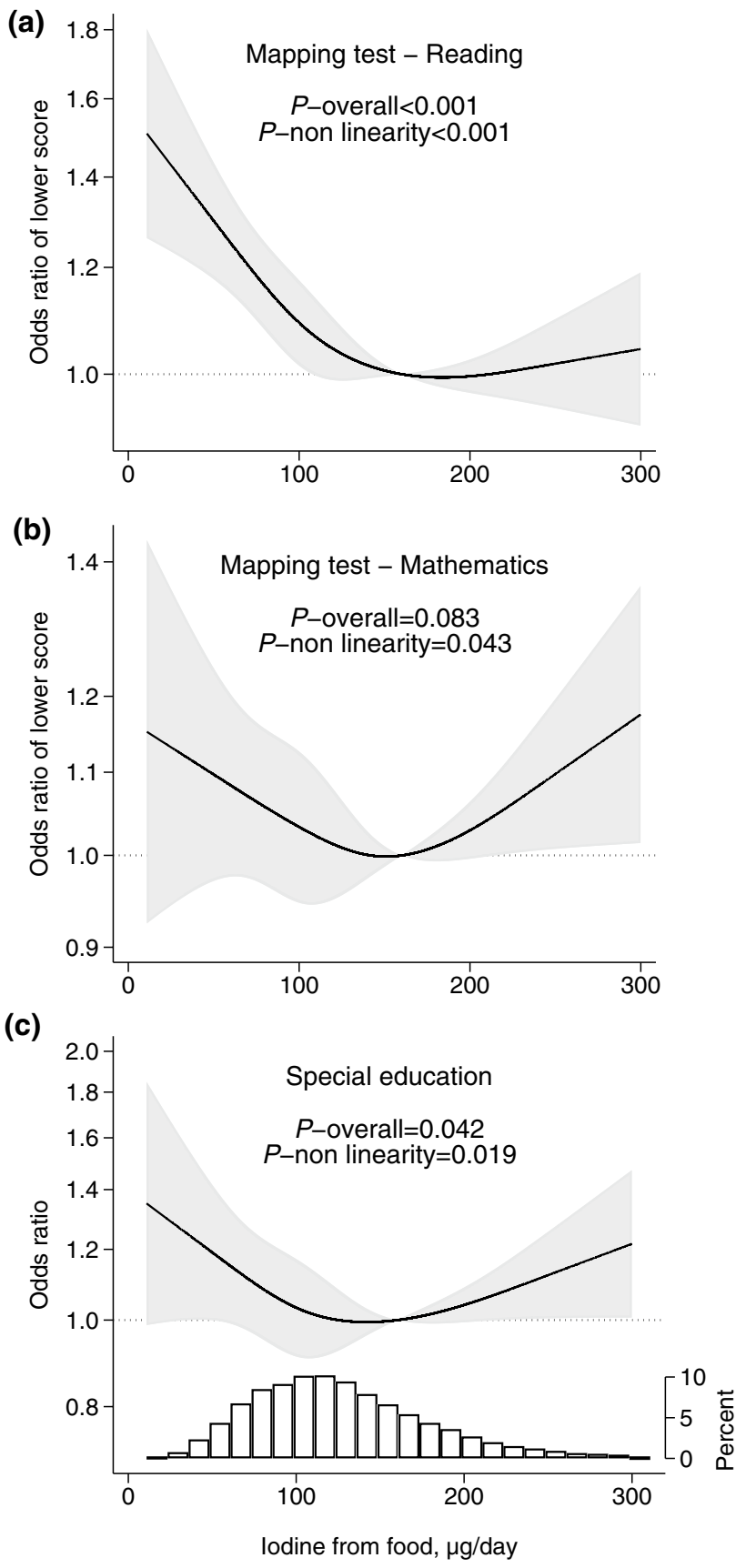

Fig. 3 Maternal iodine intake from food (in non-supplement users) and child school outcomes at age 8 years, adjusted models. Higher odds ratio indicate poorer test results $(\mathbf{a}, \mathbf{b})$ and increased likelihood of receiving special educational services (c). The reference level $(\mathrm{OR}=1)$ was set to $160 \mu \mathrm{g} /$ day. Sample size was $n=24,309$ for mapping tests in reading (a), $n=23,527$ for mathematics (b), $n=24,806$ for special education (c). The histogram in c represents the distribution of iodine intake. For crude models, see Supplementary Figure S8 (Online Resource 1)

measure of maternal iodine intake, and that the exposure was not modelled continuously. As a consequence, optimal 
Table 2 Iodine intake from food in pregnancy and language and learning at age 8 years in non-supplement users, adjusted models

\begin{tabular}{|c|c|c|c|c|c|c|}
\hline \multirow[t]{4}{*}{ Iodine intake ( $\mu \mathrm{g} /$ day $)$} & Language skills ${ }^{\mathrm{a}}$ & Reading skills ${ }^{\mathrm{a}}$ & Writing skills $^{\mathrm{a}}$ & $\begin{array}{l}\text { Mapping test } \\
\text { Reading }\end{array}$ & $\begin{array}{l}\text { Mapping test } \\
\text { Mathematics }\end{array}$ & Special education \\
\hline & $n$ & $n$ & $n$ & $n$ & $n$ & $n / N(\%)$ \\
\hline & 24,643 & 19,492 & 19,483 & 24,309 & 23,527 & $1756 / 24,806(7.1 \%)$ \\
\hline & Std. beta $(95 \%$ CI $)$ & Std. beta $(95 \%$ CI $)$ & Std. beta $(95 \%$ CI $)$ & OR $(95 \% \mathrm{CI})$ & OR $(95 \% \mathrm{CI})$ & OR $(95 \% \mathrm{CI})$ \\
\hline 25 & $0.07(0.00,0.13)$ & $0.09(0.02,0.17)$ & $0.11(0.03,0.18)$ & $1.43(1.23,1.66)$ & $1.13(0.94,1.36)$ & $1.29(1.00,1.67)$ \\
\hline 50 & $0.06(0.01,0.11)$ & $0.08(0.03,0.13)$ & $0.09(0.03,0.14)$ & $1.30(1.18,1.43)$ & $1.10(0.97,1.24)$ & $1.19(1.00,1.42)$ \\
\hline 75 & $0.06(0.02,0.09)$ & $0.06(0.02,0.10)$ & $0.07(0.03,0.11)$ & $1.18(1.10,1.28)$ & $1.06(0.97,1.16)$ & $1.10(0.96,1.25)$ \\
\hline 100 & $0.04(0.01,0.08)$ & $0.04(0.00,0.08)$ & $0.05(0.01,0.08)$ & $1.09(1.01,1.17)$ & $1.03(0.95,1.13)$ & $1.03(0.91,1.17)$ \\
\hline 125 & $0.03(0.01,0.05)$ & $0.02(0.00,0.04)$ & $0.02(0.00,0.05)$ & $1.04(0.99,1.08)$ & $1.01(0.96,1.07)$ & $1.00(0.92,1.08)$ \\
\hline 160 (ref) & 0 & 0 & 0 & 1 & 1 & 1 \\
\hline 200 & $-0.01(-0.02,0.00)$ & $0.00(-0.02,0.01)$ & $0.00(-0.01,0.02)$ & $1.00(0.97,1.03)$ & $1.03(1.00,1.06)$ & $1.04(0.99,1.09)$ \\
\hline 225 & $-0.01(-0.03,0.01)$ & $0.00(-0.03,0.03)$ & $0.02(-0.01,0.04)$ & $1.01(0.96,1.06)$ & $1.06(1.00,1.12)$ & $1.08(1.00,1.16)$ \\
\hline 250 & $-0.01(-0.04,0.03)$ & $0.01(-0.04,0.05)$ & $0.03(-0.01,0.07)$ & $1.02(0.94,1.10)$ & $1.10(1.01,1.20)$ & $1.12(1.00,1.26)$ \\
\hline 300 & $-0.01(-0.07,0.05)$ & $0.02(-0.06,0.10)$ & $0.06(-0.01,0.13)$ & $1.04(0.92,1.19)$ & $1.18(1.01,1.36)$ & $1.22(1.01,1.47)$ \\
\hline$p$ overall & $p=0.013$ & $p=0.019$ & $p=0.004$ & $p<0.001$ & $p=0.083$ & $p=0.042$ \\
\hline$p$ non-linearity & $p=0.16$ & $p=0.096$ & $p=0.004$ & $p<0.001$ & $p=0.043$ & $p=0.019$ \\
\hline
\end{tabular}

Results are from multivariable regression analysis adjusting for confounders and for random effects of sibling clusters

${ }^{\text {a }}$ Standardized beta $>0$ indicate poorer skills

${ }^{\mathrm{b}}$ Odds ratio $>1$ indicate increased risk of attaining poorer test results

intake was not explored and many participants may have been misclassified as deficient/not deficient.

We included a spot-UIC in mid pregnancy as an alternative measure of habitual iodine intake since data on maternal UIC was available for $n=2001$ pregnant women. The null findings for UIC and outcomes (Supplementary Figures S11-S12, Online Resource 1) did not support our results that maternal habitual iodine intake was associated with the outcomes, but the seemingly conflicting results might have several explanations. Firstly, a single spot-UIC is a poor measure of habitual iodine intake at an individual level [40]. König et al. found that a minimum of ten repeated spot-UICs are needed to reliably estimate individual iodine intake [41]. Secondly, the subsample with UIC measurements was not a random sample of MoBa participants. They were selected from highly dedicated participants with complete datasets of questionnaires and biological samples up to child age 3 years, and the sample did not include children with language difficulties, or those with suspected or diagnosed autism. This reduces the power to identify potential associations with language and learning outcomes. In fact, we found that in this subsample, association curves between calculated iodine intake by the FFQ and outcomes were different from the total sample, and were more in agreement with the UIC findings (Supplementary Figures S11-S12, Online Resource 1).

We have previously reported that low maternal iodine intake was associated with child ADHD symptoms in the same population of 8-years-old MoBa-children [13]. In sensitivity analyses, we found that adjusting for maternally reported ADHD symptoms at child age 8 years did not change the results markedly (Supplementary Figures S9-S10, Online Resource 1), demonstrating that the associations between iodine intake with child language and learning were partly independent of score on ADHD-symptoms.

\section{lodine intake from supplements}

We have previously reported that women in MoBa who initiated use of iodine-containing supplements in the first trimester gave birth to children with more behaviour problems at age 3 [12] and 8 years [13] and increased risk of ADHD diagnosis by age 6-14 years [13]. However, iodine supplement use was not associated with child language- or motor skills at 3 years [12]. In the present study, there was no significant association between maternal use of iodinecontaining supplements and child language and learning at 8 years. Summarized, results from MoBa are consistent in demonstrating no beneficial effects of iodine supplement use in pregnancy, but inconclusive as to whether it can be potentially harmful. Initiating use in pregnancy might be too late to compensate for a depleted maternal iodine store. The "jury is still out" on this question for areas of mild-to-moderate ID as recently concluded in a Cochrane review [22]. Nevertheless, the optimal strategy to prevent impairments 
caused by ID is to secure an adequate iodine status well before conception for all women of childbearing age [42].

\section{Strengths and limitations}

Strengths of this study include the large size, prospective- and population-based design, and the substantial data collection allowing to control for a range of confounders. Additionally, in Norway there is a large variation in habitual iodine intake since only milk and salt-water fish are important food sources of iodine in the Norwegian diet [43]. Consequently, we could study a wide range of iodine intake with flexible modelling techniques and explore potential non-linear associations. The multiple outcomes on child language and learning included results on mapping tests and whether the child was granted special education. These outcomes are more objective than the subjective evaluation of the child's language, reading and writing skills evaluated and reported by the mother which may include substantial measurement error. Child language skills were also measured in the 3-year questionnaire [12], and ideally, we would have modelled this repeated outcome longitudinally. Unfortunately this was not feasible since the instruments used were not the same at ages 3 and 8 , and consequently did not measure the exact same dimensions.

Calculating iodine intake by an FFQ is inaccurate, both due to a natural variation of iodine content of food, limited quality of the data on food iodine content, the FFQ not covering all possible food and drink alternatives, deliberate or undeliberate misreporting, and an FFQ being a survey format requiring some literacy skills to complete correctly. Nevertheless, the previous validation study showed acceptable agreement between the MoBa FFQ calculations, $24 \mathrm{~h}$ UIC, and a 4 days weighed-food dairy [35]. Additionally, since there are few food sources of iodine in Norway, a person's iodine intake is largely dependent on individual food choices and can be easier to estimate than many other nutrients. In the FFQ, women were asked to report their habitual food intake since the beginning of pregnancy. The results of this study might reflect not only iodine intake during pregnancy but also habitual iodine intake prior to pregnancy and thus maternal iodine stores.

The low participation rate in MoBa (41\%) is a concern. Women participating in MoBa are more often nulliparous, non-smokers, older and better educated than non-participants [44]. These are attributes generally associated with healthier diet and lifestyles, and yet both UIC and calculated iodine intake confirmed insufficient iodine intake, and there is little reason to expect that non-participants would have higher iodine intake than participants. Loss to followup is another concern, and only $35 \%$ of recruited women completed the 8-year questionnaire. Loss to follow-up is inevitable and commonly leads to selection bias and loss of statistical power [45]. In this study, iodine intake from food and iodine supplement use did not differ between responders and non-responders to the 8 years questionnaire. Still, we cannot exclude that loss to follow-up have influenced the results. Finally, as in all epidemiological studies, residual confounding might still be present due to the observational design, and thus we cannot make causal inference based on the results.

\section{Clinical relevance and implications}

Although the estimated effects of mild-to-moderate ID in this study are small, the high prevalence of insufficient maternal iodine intake worldwide indicates that a substantial proportion of children might not reach their full developmental potential as a consequence of maternal mild-tomoderate ID. In MoBa, $69 \%$ had a calculated iodine intake from food $<150 \mu \mathrm{g} /$ day which was associated with poorer child outcomes. In Europe, two-thirds of countries that have assessed iodine nutrition in pregnant women have reported inadequate intakes [46]. The cost of insufficient iodine nutrition is high both at the individual and societal level [18], whereas the cost of salt iodization, the primary strategy recommended by the WHO, is low [42]. Our findings support the current recommendations by the WHO that it is of vital importance to secure sufficient iodine intake of $>150 \mu \mathrm{g} /$ day in women of childbearing age [21].

In Norway, the health authorities have now, since 2017, initiated several actions to prevent ID. The national guidelines for a healthy diet now specifies that three portions of dairy products per day can contribute to secure an adequate intake of iodine and calcium. They recommend iodine supplements for women of childbearing age, pregnant, and lactating women who have a low milk/yoghurt intake. In addition, they are currently evaluating strategies to increase iodine intake by salt iodization.

\section{Conclusions}

A low habitual iodine intake in pregnant women, i.e., lower than the recommended daily intake for non-pregnant women, was associated with mothers reporting slightly poorer child language, school performance, and increased likelihood of special educational services at child age 8 years. We found no indications of benefits or harm of using iodine-containing supplements in pregnancy. Initiating use in pregnancy might be too late. 
Acknowledgements We are grateful to all the participating families in Norway who take part in this on-going cohort study. The Norwegian Mother and Child Cohort Study is supported by the Norwegian Ministry of Health and the Ministry of Education and Research, NIH/ NIEHS (contract no N01-ES-75558), NIH/NINDS (Grant no. 1 UO1 NS 047537-01 and Grant no. 2 UO1 NS 047537-06A1). MHA was supported by a 4 years Grant from the Norwegian Research Council (Grant no. 241430) and the Norwegian dairy company TINE SA.

Author contributions All authors contributed in designing the study; MHA performed the statistical analysis with support from IHC and ALB; MHA wrote the first draft of the manuscript; ALB had primary responsibility for the final content; all authors read and approved the final manuscript.

\section{Compliance with ethical standards}

Ethical approval MoBa is conducted according to the guidelines laid down in the Declaration of Helsinki and written informed consent was obtained from all participants. MoBa has obtained a license from the Norwegian Data Inspectorate. The current study was approved by The Regional Committee for Medical Research Ethics South East Norway $2014 / 2211$.

Conflict of interest The first author of this paper is employed by a Norwegian dairy company (TINE SA), and she participates in this project as an industrial Ph.D.-student financed partly by the dairy company and partly by The Research Council of Norway. This project is designed, owned and administered by The Norwegian Institute of Public Health and analysis of the data follow from protocol. All results of analysis in the project are to be published regardless of the results. The other authors have no conflicts of interest.

Open Access This article is distributed under the terms of the Creative Commons Attribution 4.0 International License (http://creativeco mmons.org/licenses/by/4.0/), which permits unrestricted use, distribution, and reproduction in any medium, provided you give appropriate credit to the original author(s) and the source, provide a link to the Creative Commons license, and indicate if changes were made.

\section{References}

1. Velasco I, Bath SC, Rayman MP (2018) Iodine as essential nutrient during the first 1000 days of life. Nutrients. https://doi. org/10.3390/nu10030290

2. Laurberg P, Cerqueira C, Ovesen L, Rasmussen LB, Perrild H, Andersen S, Pedersen IB, Carle A (2010) Iodine intake as a determinant of thyroid disorders in populations. Best Pract Res Clin Endocrinol Metab 24(1):13-27. https://doi.org/10.1016/j. beem.2009.08.013

3. Zimmermann MB, Boelaert K (2015) Iodine deficiency and thyroid disorders. Lancet Diabetes Endocrinol 3(4):286-295. https ://doi.org/10.1016/S2213-8587(14)70225-6

4. Shi X, Han C, Li C, Mao J, Wang W, Xie X, Li C, Xu B, Meng T, Du J, Zhang S, Gao Z, Zhang X, Fan C, Shan Z, Teng W (2015) Optimal and safe upper limits of iodine intake for early pregnancy in iodine-sufficient regions: a cross-sectional study of 7190 pregnant women in China. J Clin Endocrinol Metab 100(4):1630 1638. https://doi.org/10.1210/jc.2014-3704

5. Obregon MJ, Escobar del Rey F, Morreale de Escobar G (2005) The effects of iodine deficiency on thyroid hormone deiodination. Thyroid 15(8):917-929. https://doi.org/10.1089/thy.2005.15.917
6. Zimmermann MB (2010) Iodine deficiency in industrialised countries. Proc Nutr Soc 69(1):133-143. https://doi.org/10.1017/S0029 665109991819

7. Pearce EN, Andersson M, Zimmermann MB (2013) Global iodine nutrition: Where do we stand in 2013? Thyroid 23(5):523-528

8. Glinoer D (2007) The importance of iodine nutrition during pregnancy. Public Health Nutr 10(12A):1542-1546

9. McLeod DS, McIntyre HD (2010) Subclinical hypothyroidism and related biochemical entities in pregnancy: implications and management. Obstet Med 3(4):139-144. https://doi.org/10.1258/ om.2010.100023

10. World Health Organization (2007) Iodine deficiency in Europe: a continuing public health problem. In: Andersson M, de Benoist B, Darnton-Hill I et al (eds) World Health Organization, Geneva

11. Abel MH, Korevaar TIM, Erlund I, Villanger GD, Caspersen IH, Arohonka P, Alexander J, Meltzer HM, Brantsaeter AL (2018) Iodine intake is associated with thyroid function in mild- to moderately iodine deficient pregnant women. Thyroid 28:1359-1371. https://doi.org/10.1089/thy.2018.0305

12. Abel MH, Caspersen IH, Meltzer HM, Haugen M, Brandlistuen RE, Aase H, Alexander J, Torheim LE, Brantsaeter AL (2017) Suboptimal maternal iodine intake is associated with impaired child neurodevelopment at 3 years of age in the Norwegian Mother and Child Cohort Study. J Nutr 147(7):1314-1324. https ://doi.org/10.3945/jn.117.250456

13. Abel MH, Ystrom E, Caspersen IH, Meltzer HM, Aase H, Torheim LE, Askeland RB, Reichborn-Kjennerud T, Brantsaeter AL (2017) Maternal iodine intake and offspring attention-deficit/ hyperactivity disorder: results from a large prospective cohort study. Nutrients. https://doi.org/10.3390/nu9111239

14. Bath SC, Steer CD, Golding J, Emmett P, Rayman MP (2013) Effect of inadequate iodine status in UK pregnant women on cognitive outcomes in their children: results from the Avon Longitudinal Study of Parents and Children (ALSPAC). Lancet 382(9889):331-337. https://doi.org/10.1016/S0140 $-6736(13) 60436-5$

15. Hynes KL, Otahal P, Hay I, Burgess JR (2013) Mild iodine deficiency during pregnancy is associated with reduced educational outcomes in the offspring: 9-year follow-up of the Gestational Iodine Cohort. J Clin Endocrinol Metab 98(5):1954-1962

16. Hynes KL, Otahal P, Burgess JR, Oddy WH, Hay I (2017) Reduced educational outcomes persist into adolescence following mild iodine deficiency in utero, despite adequacy in childhood: 15-year follow-up of the Gestational Iodine Cohort investigating auditory processing speed and working memory. Nutrients. https://doi.org/10.3390/nu9121354

17. Wei W, Wang Y, Dong J, Wang Y, Min H, Song B, Shan Z, Teng W, Xi Q, Chen J (2015) Hypothyroxinemia induced by maternal mild iodine deficiency impairs hippocampal myelinated growth in lactational rats. Environ Toxicol 30(11):1264-1274. https:// doi.org/10.1002/tox.21997

18. Monahan M, Boelaert K, Jolly K, Chan S, Barton P, Roberts TE (2015) Costs and benefits of iodine supplementation for pregnant women in a mildly to moderately iodine-deficient population: a modelling analysis. Lancet Diabetes Endocrinol 3(9):715-722. https://doi.org/10.1016/S2213-8587(15)00212-0

19. NNR12 Project Group (2014) Iodine. In: in Nordic nutrition recommendations 2012, integrating nutrition and physical activity, 5th edn. Nordic Council of Ministers, Copenhagen, pp 583-590

20. EFSA NDA Panel (EFSA Panel on Dietetic Products Nutrition and Allergies) (2014) Scientific opinion on dietary reference values for iodine. EFSA J 12(5):3660. https://doi.org/10.2903/j. efsa.2014.3660 doi

21. World Health Organization, United Nations Children's Fund, International Council for Control of Iodine Deficiency Disorders (2007) Assessment of iodine deficiency disorders and 
monitoring their elimination: a guide for programme managers, 3rd edn. World Health Organization, Geneva

22. Harding KB, Pena-Rosas JP, Webster AC, Yap CM, Payne BA, Ota E, De-Regil LM (2017) Iodine supplementation for women during the preconception, pregnancy and postpartum period. Cochrane Database Syst Rev 3:CD011761. https://doi. org/10.1002/14651858.CD011761.pub2

23. Rebagliato M, Murcia M, Espada M, Alvarez-Pedrerol M, Bolumar F, Vioque J, Basterrechea M, Blarduni E, Ramon R, Guxens M, Foradada CM, Ballester F, Ibarluzea J, Sunyer J (2010) Iodine intake and maternal thyroid function during pregnancy. Epidemiology 21(1):62-69. https://doi.org/10.1097/EDE.0b013 e3181c1592b

24. Moleti M, Di Bella B, Giorgianni G, Mancuso A, De Vivo A, Alibrandi A, Trimarchi F, Vermiglio F (2011) Maternal thyroid function in different conditions of iodine nutrition in pregnant women exposed to mild-moderate iodine deficiency: an observational study. Clin Endocrinol (Oxf) 74(6):762-768. https:// doi.org/10.1111/j.1365-2265.2011.04007.x

25. Magnus P, Birke C, Vejrup K, Haugan A, Alsaker E, Daltveit AK, Handal M, Haugen M, Hoiseth G, Knudsen GP, Paltiel L, Schreuder P, Tambs K, Vold L, Stoltenberg C (2016) Cohort profile update: The Norwegian Mother and Child Cohort Study (MoBa). Int J Epidemiol 45(2):382-388. https://doi. org/10.1093/ije/dyw029

26. Irgens LM (2000) The Medical Birth Registry of Norway. Epidemiological research and surveillance throughout 30 years. Acta Obstet Gynecol Scand 79(6):435-439

27. Vrijheid M, Slama R, Robinson O, Chatzi L, Coen M, van den Hazel P, Thomsen C, Wright J, Athersuch TJ, Avellana N, Basagana X, Brochot C, Bucchini L, Bustamante M, Carracedo A, Casas M, Estivill X, Fairley L, van Gent D, Gonzalez JR, Granum B, Grazuleviciene R, Gutzkow KB, Julvez J, Keun HC, Kogevinas M, McEachan RR, Meltzer HM, Sabido E, Schwarze PE, Siroux V, Sunyer J, Want EJ, Zeman F, Nieuwenhuijsen MJ (2014) The human early-life exposome (HELIX): project rationale and design. Environ Health Perspect 122(6):535-544. https://doi.org/10.1289/ehp.1307204

28. Norwegian Institute of Public Health Website (2017) MoBa Food Frequency Questionnaire (English translation). http://www.webci tation.org/6u5JMPcZg. Accessed 9 Oct 2017

29. Meltzer HM, Brantsaeter AL, Ydersbond TA, Alexander J, Haugen M (2008) Methodological challenges when monitoring the diet of pregnant women in a large study: experiences from the Norwegian Mother and Child Cohort Study (MoBa). Matern Child Nutr 4(1):14-27. https://doi.org/10.1111/j.1740-8709.2007.00104 .x

30. Dahl L, Johansson L, Julshamn K, Meltzer HM (2004) The iodine content of Norwegian foods and diets. Public Health Nutr 7(4):569-576. https://doi.org/10.1079/PHN2003554

31. Dahl L, Opsahl JA, Meltzer HM, Julshamn K (2003) Iodine concentration in Norwegian milk and dairy products. Br J Nutr 90(3):679-685

32. Haugen M, Brantsaeter AL, Alexander J, Meltzer HM (2008) Dietary supplements contribute substantially to the total nutrient intake in pregnant Norwegian women. Ann Nutr Metab 52(4):272-280. https://doi.org/10.1159/000146274
33. Brantsaeter AL, Haugen M, Alexander J, Meltzer HM (2008) Validity of a new food frequency questionnaire for pregnant women in the Norwegian Mother and Child Cohort Study (MoBa). Matern Child Nutr 4(1):28-43. https://doi.org/10.111 1/j.1740-8709.2007.00103.x

34. Brantsaeter AL, Haugen M, Hagve TA, Aksnes L, Rasmussen SE, Julshamn K, Alexander J, Meltzer HM (2007) Self-reported dietary supplement use is confirmed by biological markers in the Norwegian Mother and Child Cohort Study (MoBa). Ann Nutr Metab 51(2):146-154. https://doi.org/10.1159/000103275

35. Brantsaeter AL, Haugen M, Julshamn K, Alexander J, Meltzer HM (2009) Evaluation of urinary iodine excretion as a biomarker for intake of milk and dairy products in pregnant women in the Norwegian Mother and Child Cohort Study (MoBa). Eur J Clin Nutr 63(3):347-354. https://doi.org/10.1038/sj.ejcn.1602952

36. Bishop DVM (2003) Children's communication checklist, 2nd edn. Pearson Assessments, London

37. Bishop DV, Laws G, Adams C, Norbury CF (2006) High heritability of speech and language impairments in 6-year-old twins demonstrated using parent and teacher report. Behav Genet 36(2):173-184. https://doi.org/10.1007/s10519-005-9020-0

38. Norbury CF, Nash M, Baird G, Bishop D (2004) Using a parental checklist to identify diagnostic groups in children with communication impairment: a validation of the Children's Communication Checklist-2. Int J Lang Commun Disord 39(3):345-364. https:// doi.org/10.1080/13682820410001654883

39. Sparrow SS, Cicchetti DV, Balla DA (2005) Vineland Adaptive Behaviour Scale-II. American Guidance Service, Minnesota

40. Pearce EN, Caldwell KL (2016) Urinary iodine, thyroid function, and thyroglobulin as biomarkers of iodine status. Am J Clin Nutr 104(Suppl 3):898S-901S. https://doi.org/10.3945/ajcn.115.11039 5

41. Konig F, Andersson M, Hotz K, Aeberli I, Zimmermann MB (2011) Ten repeat collections for urinary iodine from spot samples or 24-hour samples are needed to reliably estimate individual iodine status in women. J Nutr 141(11):2049-2054. https://doi. org/10.3945/jn.111.144071

42. Aburto N, Abudou M, Candeias V, Wu T (2014) Effect and safety of salt iodization to prevent iodine deficiency disorders: a systematic review with meta-analyses. World Health Organization, Geneva

43. Brantsaeter AL, Abel MH, Haugen M, Meltzer HM (2013) Risk of suboptimal iodine intake in pregnant Norwegian women. Nutrients 5(2):424-440. https://doi.org/10.3390/nu5020424

44. Nilsen RM, Vollset SE, Gjessing HK, Skjaerven R, Melve KK, Schreuder P, Alsaker ER, Haug K, Daltveit AK, Magnus P (2009) Self-selection and bias in a large prospective pregnancy cohort in Norway. Paediatr Perinat Epidemiol 23(6):597-608. https://doi. org/10.1111/j.1365-3016.2009.01062.x

45. Mann CJ (2003) Observational research methods. Research design II: cohort, cross sectional, and case-control studies. Emerg Med J 20(1):54-60

46. Zimmermann MB, Gizak M, Abbott K, Andersson M, Lazarus JH (2015) Iodine deficiency in pregnant women in Europe. Lancet Diabetes Endocrinol. https://doi.org/10.1016/S2213 -8587(15)00263-6 